\title{
Primary care diagnostic technology update: point-of-care testing for glycosylated haemoglobin
}

Annette Plüddemann, Christopher P Price, Matthew Thompson, Jane Wolstenholme and Carl Heneghan

\section{Clinical Question}

In the monitoring of patients with type 1 and type 2 diabetes, what advantages does point-of-care $\mathrm{HbA}_{1}$ testing provide over current practice?

\section{ADVANTAGES OVER EXISTING TECHNOLOGY}

In patients with existing diabetes $\mathrm{HbA}_{1 c}$ monitoring is usually performed every 3-6 months. It typically involves a nurse visit or phlebotomist for venepuncture, with follow-up 1-2 weeks later to discuss results. Point-of-care testing (POCT) could provide more immediate therapeutic decisions and fewer patient visits. This might result in improved diabetic control and practice efficiency.

\section{DETAILS OF TECHNOLOGY}

Blood glucose binds to haemoglobin, forming glycated haemoglobin $\left(\mathrm{HbA}_{1 \mathrm{c}}\right)$. On the basis that the half life of a red blood cell is approximately 120 days, the circulating $\mathrm{HbA}_{1 \mathrm{c}}$ level reflects the blood glucose control over the preceding 3-month period. Typically, the point of care $\mathrm{HbA}_{1 \mathrm{c}}$ device uses a finger-stick drop of blood applied to a reagent cartridge, which is then inserted in a desktop analyser, where the analysis is performed, and $\mathrm{HbA}_{1 c}$ reported (as percentage and $\mathrm{mmol} / \mathrm{mol}$ ). The time-to-result is between 5 and 10 minutes. In some of the systems it is also possible to measure the urine albumin creatinine ratio using a different reagent cassette.

\section{PATIENT GROUP AND USE}

- Patients with type 1 or type 2 diabetes mellitus to monitor glycaemic control.

\section{IMPORTANCE}

Diabetes UK reports that currently 2.6 million people are diagnosed with diabetes in the UK (5.1\% prevalence), which is on the increase in all age groups. For instance, a $70 \%$ increase in type 2 diabetes incidence is predicted in children aged $<15$ years by $2020 .^{1}$

The National Services Framework for Diabetes highlights the importance of managing diabetes in primary care. In the National Diabetes Audit for 2008-2009, $88 \%$ of records from people with type 1 diabetes and $94 \%$ with type 2 included an $\mathrm{HbA}_{1 \mathrm{c}}$ measurement.

NICE guidance states, providing there is no disabling hypoglycaemia, the target $\mathrm{HbA}_{1 c}$ concentration for children, young people, and adults with type 1 diabetes is $7.5 \% \mathrm{HbA}_{1 c}$ and if the $\mathrm{HbA}_{1 c}$ is consistently $>9.5 \%$ additional support should be offered.

\section{PREVIOUS RESEARCH}

Accuracy compared to existing technology

A recent study comparing eight $\mathrm{HbA}_{1 \mathrm{c}}$ measurement devices using three Clinical Laboratory Standards Institute Protocols to investigate imprecision, accuracy, and bias reported that only the DCA Vantage ${ }^{\text {TM }}$ (Siemens) and Afinion ${ }^{\text {TM }}$ (Axis-Shield) met the acceptance criteria (coefficient of variation $<3 \%$ ) in the clinically relevant range. ${ }^{2}$

\section{Impact compared to existing technology}

A trial which randomised patients with type 1 and 2 diabetes attending an academic diabetes centre to immediate feedback of $\mathrm{HbA} A_{1 c}$ results compared to standard care, found significant improvement in glycaemic control at 6 and 12 months. ${ }^{3}$ POCT was positively received by both patients and physicians. A prospective controlled trial comparing POCT and standard laboratory testing in an urban primary care

A Plüddemann, PhD, director of Diagnostic Horizon Scanning Programme; CP Price, $P h D$, professor in clinical biochemistry \& clinical director of the Cumbria and Lancashire Pathology Commissioning Network; M Thompson, DPhil, MRCGP, GP \& senior clinical scientist; J Wolstenholme, $B A, M S c, P h D$, health economics senior researcher; C Heneghan, MA, MRCGP, DPhil, clinical reader, Primary Care Diagnostic Horizon Scanning, Centre for Monitoring and Diagnosis Oxford, University of Oxford, Oxford.

Address for correspondence

Dr Annette Plüddemann, Primary Care Diagnostic Horizon Scanning, Centre for Monitoring and Diagnosis Oxford, Department of Primary Health Care, University of Oxford, Oxford, OX3 7LF. E-mail: horizonscanning@dphpc.ox.ac.uk

Submitted: 30 June 2010; Editor's response: 19 November 2010; final acceptance: 23 August 2010.

(c)British Journal of General Practice 2011; 61: 139-140.

DOI: 10.3399/bjgp11X556290 
clinic showed POCT availability resulted in more frequent intensification of therapy when baseline $\mathrm{HbA}_{1 c}$ was $27.0 \% \quad(51 \%$ versus $32 \%$ of patients, $P=0.01$ ). In the subsequent two follow-up visits, $\mathrm{HbA}_{1 c}$ fell significantly in the POCT group (from 8.4 to $8.1 \%$, $P=0.04$ ) but not in the standard care group (from 8.1 to $8.0 \%, P=0.31) .{ }^{4}$ A primary care study among patients receiving active insulin titration (weekly monitoring) showed POCT resulted in a greater proportion achieving $\mathrm{HbA}_{1 c}<7.0 \%$ compared to those with laboratory measurement. ${ }^{5}$

In contrast, a second randomised controlled trial conducted in general practice in Leicestershire, UK, showed no significant change in the proportion of patients with $\mathrm{HbA}_{1 \mathrm{c}}<7.0 \%$ when using POCT at 12months' follow-up. ${ }^{6}$ However the investigators noted it was 'difficult to organise their management of patients in such a way as to maximise the benefit from rapid testing for intervention group patients', implying the results were not discussed with the patient at the time of the clinic visit. The study also indicated that POCT was highly acceptable to patients and staff and confirmed there may be benefits such as time saving, reduced anxiety, and impact on patient management and job satisfaction. ${ }^{7}$ However, the study also identified high pre-existing levels of satisfaction with diabetes care and the survey failed to confirm increased patient satisfaction as a result of rapid testing.

A large randomised controlled trial undertaken in Australia $^{8}$ found that POCT was non-inferior to pathology laboratory testing in relation to the proportion of patients showing an improvement in their test results from baseline: $\mathrm{HbA}_{1 \mathrm{c}}$ (57.3\% [POCT] versus $44.9 \%$ [laboratory]; difference, $12.4 \% \quad[90 \%$ confidence interval $=6.5 \%$ to $18.4 \%], P<0.001$ ).

\section{Cost-effectiveness and economic impact}

A study comparing laboratory and nurse near-patient testing for several diagnostic tests, including $\mathrm{HbA}_{1 \mathrm{c}}$, found that POCT led to improvements in the care process, significantly greater patient satisfaction, and lower mean levels of $\mathrm{HbA}_{1 c}$, but higher visit costs reflecting the greater number of tests and higher equipment costs. ${ }^{9}$ A pragmatic, randomised controlled trial where patients were randomised to receive instant results for $\mathrm{HbA}_{1 \mathrm{c}}$ or routine care found a non-statistical total cost difference of diabetes related care; $£ 390$ in the control group and $£ 370$ in the POCT group. ${ }^{6}$ However this study had not managed to change the way in which patients were managed and so presumably had not managed to influence the number of clinic visits.

A Swedish before-and-after study compared the economic costs and benefits of implementing $\mathrm{HbA}_{1 \mathrm{c}}$ home testing. ${ }^{10}$ They found a reduction in costs due to fewer clinic visits, reduction in total treatment costs, time saved and reduced labour costs in administration and sampling, reduced travel costs, and a reduction in mean $\mathrm{HbA}_{1 c}$ levels.

\section{Health Technology Assessments (HTAs)}

One relevant HTA report was identified from the UK. A study in diabetes clinics indicated providing nearpatient testing of $\mathrm{HbA} 1 \mathrm{c}$ results seemed to improve the process of care and aspects of patient satisfaction. The report recommended a prospective randomised controlled trial of near-patient testing in diabetes clinics. ${ }^{11}$

What this technology adds

The point-of-care $\mathrm{HbA}_{10}$ test could improve

management of the increasing numbers of patients with

established diabetes being managed in primary care.

\section{Relevant guidelines}

NICE clinical guidance: Diagnosis and management of type 1 diabetes in children, young people and adults. http://guidance.nice.org.uk/CG15.

\section{Funding}

The Centre for Monitoring and Diagnosis Oxford (MaDOx) is funded by the National Institute for Health Research, UK programme grant 'Development and implementation of new diagnostic processes and technologies in primary care'.

\section{Acknowledgements}

The authors would like to thank Richard Stevens and Nia Roberts for helpful discussions.

\section{Discuss this article}

Contribute and read comments about this article on the Discussion Forum: http://www.rcgp.org.uk/bjgp-discuss

\section{REFERENCES}

1. Patterson CC, Dahlquist GG, Gyürüs E, et al. Incidence trends for childhood type 1 diabetes in Europe during 1989-2003 and predicted new cases 2005-20: a multicentre prospective registration study. Lancet 2009; 373(9680): 2027-2033.

2. Lenters-Westra E, Slingerland RJ. Six of eight hemoglobin Aıc point-of-care instruments do not meet the general accepted analytical performance criteria. Clin Chem 2010; 56(1): 44-52.

3. Cagliero E, Levina EV, Nathan DM. Immediate feedback of $\mathrm{Hb} A_{i c}$ levels improves glycemic control in type 1 and insulin-treated type 2 diabetic patients. Diabetes Care 1999; 22(11): 1785-1789.

4. Miller CD, Barnes CS, Phillips LS, et al. Rapid A $A_{c}$ availability improves clinical decision-making in an urban primary care clinic. Diabetes Care 2003; 26(4): 1158-1163.

5. Kennedy L, Herman WH, Strange P, et al; GOAL AIC Team. Impact of active versus usual algorithmic titration of basal insulin and point-of-care versus laboratory measurement of $\mathrm{Hb}_{\mathrm{c}}$ on glycemic control in patients with type 2 diabetes: the Glycemic Optimization with Algorithms and Labs at Point of Care (GOAL A1C) trial. Diabetes Care 2006; 29(1): 1-8.

6. Khunti K, Stone MA, Burden AC, et al. Randomised controlled trial of near-patient testing for glycated haemoglobin in people with type 2 diabetes mellitus. Br J Gen Pract 2006; 56(528): 511-517.

7. Stone MA, Burden AC, Burden M, et al. Near patient testing for glycated haemoglobin in people with type 2 diabetes mellitus managed in primary care: acceptability and satisfaction. Diabet Med 2007; 24(7): 792-795.

8. Bubner TK, Laurence CO, Gialamas A, et al. Effectiveness of point-of-care testing for therapeutic control of chronic conditions: results from the PoCT in General Practice Trial. Med J Aust 2009; 190(11): 624-626.

9. Grieve R, Beech R, Vincent J, Mazurkiewicz J. Near patient testing in diabetes clinics: appraising the costs and outcomes. Health Technol Assess 1999; 3(15): 1-74.

10. Snellman K, Eckerbom S. Possibilities and advantages with home sampling of HbAlc: eight years experience. Diabet Med 1997; 14(5): 401-403.

11. Waugh N, Scotland G, McNamee P, et al. Screening for type 2 diabetes: literature review and economic modelling. Health Technol Assess 2007; 11(17): http://www.hta.ac.uk/execsumm/summ1117.shtml (accessed 11 Jan 2011). 